\title{
Focal adhesion kinase regulates insulin resistance in skeletal muscle
}

\author{
B. Bisht • H. L. Goel • C. S. Dey
}

Received: 31 May 2006 / Accepted: 15 October 2006 / Published online: 28 February 2007

(C) Springer-Verlag 2007

\begin{abstract}
Aims/hypothesis On the basis of our previous studies, we investigated the possible role of focal adhesion kinase (FAK) in the development of insulin resistance in skeletal muscle, a major organ responsible for insulin-stimulated glucose uptake.

Materials and methods Insulin-resistant $\mathrm{C} 2 \mathrm{C} 12$ skeletal muscle cells were transfected with FAK wild-type or FAK mutant plasmids, knocked down using small interfering RNA (siRNA), and their effects on the levels and activities of insulin-signalling molecules and on glucose uptake were determined.

Results A significant decrease in tyrosine phosphorylation of FAK in insulin-resistant $\mathrm{C} 2 \mathrm{C} 12$ cells was observed. A similar decrease was observed in skeletal muscle obtained
\end{abstract}

Electronic supplementary material The online version of this article (doi:10.1007/s00125-007-0591-6) contains supplementary material, which is available to authorised users. This contains details of the authors' contributions to the study.

\footnotetext{
Niper communication no. 389

B. Bisht $\cdot$ H. L. Goel • C. S. Dey $(\bowtie)$

Signal Transduction Research Laboratory,

Department of Biotechnology,

National Institute of Pharmaceutical Education

and Research (NIPER),

Sector 67, S.A.S. Nagar,

Chandigarh 160062, India

e-mail: csdey@niper.ac.in

Present address:

H. L. Goel

Department of Cancer Biology,

University of Massachusetts Medical School,

LRB, 364 Plantation Street,

Worcester, MA 1605, USA
}

from insulin-resistant Sprague-Dawley rats fed a high-fat diet. Increased levels of FAK in insulin-resistant $\mathrm{C} 2 \mathrm{C} 12$ skeletal muscle cells increased insulin sensitivity and glucose uptake. These effects were reversed by an increase in the level of kinase activity mutant FAK or suppression of endogenous FAK by siRNA. FAK was also found to interact downstream with insulin receptor substrate-1, phosphatidylinositol 3-kinase and protein kinase $\mathrm{C}$ and glycogen synthase kinase $3 \beta$, leading to translocation of glucose transporter 4 and resulting in the regulation of glucose uptake.

Conclusions/interpretation The present study provides strong evidence that the modulation of FAK level regulates the insulin sensitivity of skeletal muscle cells. The results demonstrate a direct role of FAK in insulin-resistant skeletal muscle cells for the first time.

Keywords FAK · Insulin resistance · siRNA ·

Skeletal muscle

$\begin{array}{ll}\begin{array}{l}\text { Abbreviations } \\ \text { 2-DOG }\end{array} & \begin{array}{l}\text { 2-deoxy }\left[{ }^{3} \mathrm{H}\right] \text { glucose } \\ \text { focal adhesion kinase } \\ \text { FAK }\end{array} \\ \begin{array}{ll}\text { GSK-3 } \beta & \text { glycogen synthase kinase } 3 \beta \\ \text { IR } & \text { insulin receptor } \\ \text { low-density microsome }\end{array} \\ \text { MF } & \begin{array}{l}\text { MCDB 201:Ham's F-12 serum-free } \\ \text { medium (1:1) }\end{array} \\ \text { MFI } & \begin{array}{l}\text { MCDB 201:Ham's F-12 serum-free } \\ \text { medium with insulin (1:1) }\end{array} \\ \text { PDBu } & \begin{array}{l}\text { phorbol 12,13-dibutyrate } \\ \text { phosphatidyl inositol 3-kinase }\end{array} \\ \text { PI3K } & \begin{array}{l}\text { phenylmethylsulphonyl fluoride } \\ \text { PMSF }\end{array} \\ \text { PKC } & \begin{array}{l}\text { protein kinase C } \\ \text { siRNA }\end{array} \\ \text { small interfering RNA }\end{array}$




\section{Introduction}

Focal adhesion kinase (FAK) is a non-receptor tyrosine kinase and is known to play a key role in integrin signalling [1]. FAK can associate with multiple cellular components, including adhesion-associated proteins and signalling molecules [2]. We have previously reported regulation of myogenesis $[3,4]$ and cell spreading $[5,6]$ by FAK as a function of its tyrosine phosphorylation in $\mathrm{C} 2 \mathrm{C} 12$ skeletal muscle cells due to insulin stimulation. Bianchi et al. [7] reported the regulation of FAK phosphorylation by glycogen synthase kinase $3 \beta$ (GSK-3 $\beta$ ) during cell spreading and migration. In addition, regulation of FAK phosphorylation by insulin stimulation in non-muscle cells has been reported [8-10]. A regulatory role of FAK in IRS-1 levels $[11,12]$ and hepatic insulin action $[13,14]$ has also been reported. Genetic studies have provided evidence for interaction between integrin and insulin signalling [15, 16]. The available literature also focuses on the role of FAK in insulin-mediated effects on the cytoskeleton [10, 17]. Recently, Huang et al. [18] have reported that a reduced level of FAK disrupts insulin action in skeletal muscle. However, the role of FAK in regulating insulin resistance in skeletal muscle, if any, and its possible pathway have not been investigated.

We had previously generated an insulin-resistant skeletal muscle model by differentiating mouse $\mathrm{C} 2 \mathrm{C} 12$ cells in the chronic presence of insulin $(100 \mathrm{nmol} / \mathrm{l})$ in serum-free medium (MFI) [19-22]. The model was validated using glucose-lowering drugs, including pioglitazone [19], metformin [20] and gliclazide [21]. This model was used in the present study to investigate the role of FAK, if any, under conditions of impaired insulin action.

\section{Materials and methods}

Materials Nutrient Mixture F-12 Ham, MCDB 201 medium and 2-deoxy $\left[{ }^{3} \mathrm{H}\right]$ glucose (2-DOG) were from Sigma Chemical Company (St Louis, MO, USA). Anti-phospho Akt (Ser473), anti-Akt, anti-phospho (Ser) GSK-3 $\beta$ and anti-GSK-3 $\beta$ antibodies were from Cell Signaling Technology (MA, USA). Anti-FAK, anti-phosphotyrosine, antiinsulin receptor (IR) and anti-IRS-1 antibodies were from Santa Cruz Biotechnology (Santa Cruz, CA, USA). Bovine insulin and anti-GLUT4 (also known as SLC2A2) was purchased from Calbiochem (CA, USA). All other reagents were from Sigma unless attributed otherwise.

Cell culture $\mathrm{C} 2 \mathrm{C} 12$ skeletal muscle cell lines (wild-type and transfectants) were maintained in DMEM supplemented with $15 \%$ FCS containing penicillin $100 \mathrm{IU} / \mathrm{ml}$ and streptomycin $100 \mu \mathrm{g} / \mathrm{ml}$ in $5 \% \mathrm{CO}_{2}$ at $37^{\circ} \mathrm{C}$ [3]. Cells at $70 \%$ confluence were differentiated in an equal mixture of MCDB 201 and Ham's F-12 medium as described previously [19] in the absence (MF, insulin-sensitive condition) or in the chronic presence of $100 \mathrm{nmol} / \mathrm{l}$ insulin (MFI, insulin-resistant condition) for 3 days.

Subcellular fractionation $\mathrm{C} 2 \mathrm{C} 12$ myotubes, pretreated with or without insulin, were washed with ice-cold PBS, scraped into buffer A (mmol/l: HEPES 20, pH 7.4, sucrose 250, EDTA 1, phenylmethylsulphonyl fluoride [PMSF] 2) with $10 \mu \mathrm{g} / \mathrm{ml}$ aprotinin and leupeptin and homogenised for $10 \mathrm{~min}$ at $4^{\circ} \mathrm{C}$, after which low-density microsome (LDM) and plasma membrane fractions were isolated by differential centrifugation [23]. Protein samples $(100 \mu \mathrm{g})$ were subjected to SDS-PAGE and western immunoblotting.

Transfection of plasmid vectors $\mathrm{C} 2 \mathrm{C} 12$ cells were stably transfected with FAK wild-type and mutant plasmids as described earlier [22].

siRNA transfection siRNA oligonucleotides against FAK targeted sequence 5'-TGCAATGGAACGAGTATTAAA-3' were designed and synthesised by Qiagen $\mathrm{GmbH}$ (Hilden, Germany). C2C12 cells were transiently transfected with FAKspecific and non-specific siRNA (400 nmol/l) using RNAifect transfection reagent (Qiagen) in reduced-serum Opti-MEM media (Gibco BRL, Carlsbad, CA, USA) according to the manufacturer's instructions, with minor modifications.

Preparation of cell lysates Cells were washed with ice-cold PBS and lysed in lysis buffer (mmol/1: HEPES 50, $\mathrm{pH} 7.4$, $\mathrm{NaCl} 150, \mathrm{MgCl}_{2} 1.5$, EGTA 1, sodium pyrophosphate 10, sodium fluoride $50, \beta$-glycerophosphate $50, \mathrm{Na}_{3} \mathrm{VO}_{4} 1$, PMSF 2) with $1 \%$ Triton $\mathrm{X}-100,10 \mu \mathrm{g} / \mathrm{ml}$ each of leupeptin, aprotonin and soyabean trypsin inhibitor at $4^{\circ} \mathrm{C}$ for $30 \mathrm{~min}$. Homogenates were centrifuged at $16,000 \mathrm{~g}$ for $15 \mathrm{~min}$ at $4^{\circ} \mathrm{C}$ [4]. Protein estimation was performed using the Bicinchoninic Acid Kit (Sigma) according to the manufacturer's instructions. Equal concentrations of lysates of all the samples were subjected to SDS-PAGE followed by western immunoblotting [3].

Tissue preparation from rats fed a high-fat diet Male Sprague-Dawley rats (Central Animal Facility, NIPER, India) were divided into two equal groups. One of the groups was fed a normal pellet diet, while the other group was fed a high-fat diet for 4 weeks. The high-fat diet comprised: powdered pellets $(364 \mathrm{~g})$, lard $(310 \mathrm{~g})$, casein $(250 \mathrm{~g})$, cholesterol $(10 \mathrm{~g})$, DL-methionine $(3 \mathrm{~g})$, Yee-sac powder $(1 \mathrm{~g})$, vitamin and mineral mix powder $(60 \mathrm{~g})$, sodium chloride $(2 \mathrm{~g})$. Biochemical analyses and tolerance tests were performed as described previously [24, 25]. Skeletal muscle from the thigh region was collected, 
washed with PBS (pH 7.4) and lysed using the lysis buffer as described earlier [4]. The use of animals for the experiments was in compliance with the guidelines of our institutional animal ethics committee.

Phosphatidyl inositol 3-kinase activity Cells were differentiated under MF and MFI conditions and were stimulated with insulin for $10 \mathrm{~min}$. Cells $(500 \mu \mathrm{g})$ were lysed and immunoprecipitated for IRS-1 [19]. IRS-1-associated activity of phosphatidyl inositol 3-kinase (PI3K) was determined with the PI3K ELISA Kit (Echelon Biosciences Inc., Salt Lake City, UT, USA) according to the manufacturer's instructions and as reported previously [26-28].

Glucose uptake assays Glucose uptake assays were performed using 2-DOG as described earlier [21].

Densitometric analysis Relative densitometric analyses of the samples were determined using Gel Doc 2000 (BioRad, Hercules, CA, USA) and Quantity One 1-D analysis software (Bio-Rad) by giving an arbitrary value of 1.0 to the respective control samples of each experiment, keeping the background value as 0 .

Statistical analysis The data are expressed as mean \pm SE. For comparison of two groups, $p$ values were calculated using the two-tailed unpaired Student's $t$ test. In all the cases $p<0.05$ was considered to be statistically significant.

\section{Results}

To determine the role of FAK in insulin resistance, if any, $\mathrm{C} 2 \mathrm{C} 12$ cells were differentiated under insulin-sensitive (MF) or insulin-resistant (MFI) conditions [19]. Cells were lysed, immunoprecipitated with anti-FAK and subjected to western immunoblotting with anti-phosphotyrosine or antiFAK antibody (Fig. 1a). FAK tyrosine phosphorylation was found to be reduced by $40.3 \pm 0.01 \%$ in insulin-resistant cells, with no change in its protein level (Fig. 1a). To determine whether FAK tyrosine phosphorylation is affected in insulin-resistant animals, skeletal muscles were isolated from the high-fat-diet-fed Sprague-Dawley rats $[24,25]$ and examined for FAK phosphorylation. Rats fed high-fat diets show significant elevations in body weight, plasma insulin, plasma glucose, plasma triacylglycerol and plasma cholesterol levels, resulting in insulin resistance [24, 25]. Skeletal muscle isolated from normal and high-fat-dietfed Sprague-Dawley rats were immunoprecipitated with anti-FAK and subjected to western immunoblotting with anti-phosphotyrosine or anti-FAK antibody. A decrease $(57.5 \pm 0.04 \%)$ in tyrosine phosphorylation was observed a

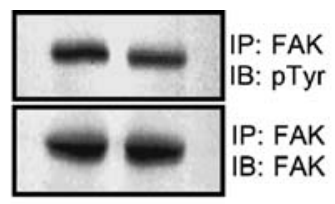

b

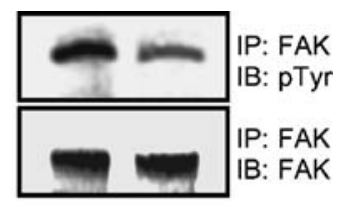

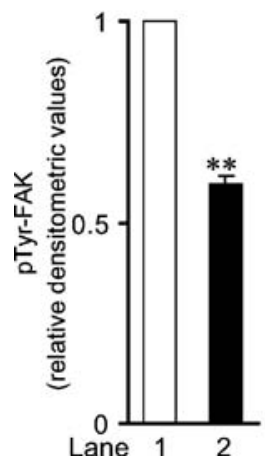

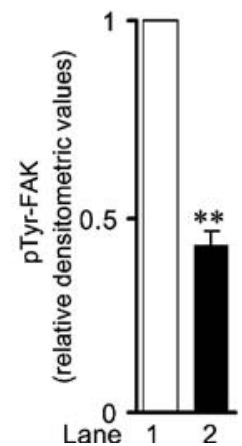

Fig. 1 FAK tyrosine phosphorylation in insulin-resistant skeletal muscle. a $\mathrm{C} 2 \mathrm{C} 12$ cells were differentiated in serum-free medium in the absence (MF) or chronic presence of $100 \mathrm{nmol} / \mathrm{l}$ insulin (MFI) for 3 days. Protein extracts $(200 \mu \mathrm{g}$ each) were immunoprecipitated with anti-FAK antibody, subjected to western immunoblotting and probed with anti-phosphotyrosine or anti-FAK antibody. Bars represent relative densitometric values of pTyr-FAK. Lane $1, \mathrm{C} 2 \mathrm{C} 12$ cells differentiated in MF medium; lane 2, $\mathrm{C} 2 \mathrm{C} 12$ cells differentiated in MFI medium. Experiments were repeated three times and a representative result is shown. Values are mean \pm SE. ${ }^{*} p<0.01$. Open bars, MF; filled bars, MFI. b Protein lysates $(200 \mu \mathrm{g})$ from skeletal muscle of normal (control) and high-fat diet-fed (insulin-resistant) rats were immunoprecipitated with anti-FAK antibody, subjected to western immunoblotting and probed with anti-phosphotyrosine or anti-FAK antibody. Bars represent relative densitometric values of pTyr-FAK. Lane 1; normal rat, lane 2; high-fat diet-fed rat. Experiments were repeated six times and a representative result is shown. Values are mean \pm SE. ${ }^{* *} p<0.01$. Open bars, normal rats; filled bars, rats fed high-fat diet. IP, immunoprecipitated; IB, immunoblotted

in high-fat-diet-fed Sprague-Dawley rats compared with normal rats (Fig. 1b), with no change in its protein level (Fig. 1b). The data thus confirmed the in vitro findings and strongly emphasised the possible involvement of FAK in skeletal muscle insulin resistance.

The role of FAK could be shown either by generating FAK knockout mice or use specific inhibitors. However, FAK knockout studies could not be performed because of reported embryonic lethality $[29,30]$ and there is no inhibitor of FAK available [2]. Therefore, to address the issue we undertook several lines of study. We generated the C2C12 cell line, which overexpresses haemagglutinin (HA)tagged plasmid constructs containing the wild-type gene encoding FAK $\left(\mathrm{C}_{2} \mathrm{FAK}^{\mathrm{wt} /+}\right)$ or a mutation in the major autophosphorylation site, tyrosine-397 (Y397F; mutant FAK gene, $\mathrm{C} 2 \mathrm{FAK}^{\mathrm{mut} /+}$ ) (Electronic supplementary material [ESM] Fig. 1). C2 $\mathrm{FAK}^{\mathrm{wt} /+}$ and $\mathrm{C} 2 \mathrm{FAK}^{\mathrm{mut} /+}$ cells showed $52 \pm 0.1$ and $50 \pm 0.1 \%$ overexpression of the $\mathrm{FAK}^{\mathrm{wt}}$ and FAK $^{\text {mut }}$ genes, respectively, compared with untransfected 
cells (Fig. 2a). No significant change in cellular morphology (ESM Fig. 2), growth rates and cell death due to transfection was observed, as shown by Trypan Blue exclusion and the TUNEL (terminal deoxyribonucleotide transferase-mediated dUTP nick end labelling) assay (data not shown).

Transfected cells were then subjected to the MF and MFI conditions and tyrosine phosphorylation of FAK was assayed (Fig. 2b). Under both conditions, tyrosine phosphorylation of $\mathrm{C}_{2} \mathrm{FAK}^{\mathrm{wt} /+}$ cells increased by $56 \pm 0.06$ and $42.2 \pm 0.03 \%$ over their respective controls (Fig. $2 \mathrm{~b}$, lane 3 vs lane $1, p<0.01$; lane 4 vs lane $2, p<0.01$ ). Although tyrosine phosphorylation of FAK in the MFI condition was always less than in the MF condition, insulin-resistant $\mathrm{C}_{2} \mathrm{FAK}^{\mathrm{wt} /+}$ cells exhibited increased tyrosine phosphorylation, and the level of phosphorylation was similar to that of insulin-sensitive C2FAK ${ }^{\mathrm{wt}}$ cells (Fig. 2b, lane 4 vs lane 1). Tyrosine phosphorylation of FAK in $\mathrm{C}_{2} \mathrm{FAK}^{\mathrm{mut} /+}$ cells under the MF or MFI condition was less (by 29.4 \pm 0.06 and $25.8 \pm 0.05 \%$, respectively) than in their respective controls (Fig. 2b, lane 5 vs lane 1, $p<0.01$; lane 6 vs lane 2, $p<0.05)$. The data therefore suggest correlation between FAK phosphorylation and insulin resistance.

To assess the functional contribution of altered FAK protein level and/or its activation in the pathogenesis of insulin resistance, glucose uptake was measured in the abovementioned cell lines cultured under the MF or MFI condition. Insulin-sensitive $\mathrm{C}_{2} \mathrm{FAK}^{\mathrm{wt} /+}$ cells showed a $40.5 \pm 0.48 \%$ increase in insulin-stimulated 2-DOG uptake compared with ${\mathrm{C} 2 \mathrm{FAK}^{\mathrm{wt}}}^{\mathrm{w}}$ cells (Fig. 2c, lane 3 vs lane $1, p<0.01$ ). For detailed data with and without insulin stimulation see ESM Fig. 3. Under insulin-resistant conditions, $\mathrm{C}_{2} \mathrm{FAK}^{\mathrm{wt} /+}$ cells exhibited increased glucose uptake $(28.6 \pm 0.61 \%)$ compared with $\mathrm{C}_{2} \mathrm{FAK}^{\mathrm{wt}}$ cells (Fig. 2c, lane 4 vs lane 2, $p<0.01$ ), comparable with that observed in insulin-sensitive $\mathrm{C}_{2} \mathrm{FAK}^{\mathrm{wt}}$ cells (Fig. 2c, lane 4 vs lane 1). Cells with increased levels of FAK were thus protected from the development of hyperinsulinaemia-induced insulin resistance. However, $\mathrm{C}_{2} \mathrm{FAK}^{\mathrm{mut} /+}$ cells developed insulin resistance as there was no insulin-stimulated increase in glucose uptake (Fig. 2c, lane 5 vs lane $1, p<0.01$ and lane 6 vs lane $2, p<0.01$ ).

To further establish the role of FAK, the siRNA approach was used. Maximum downregulation (84.6 \pm $0.01 \%$ ) of FAK was observed at $400 \mathrm{nmol} / 1$ of siRNA (ESM Fig. 4a), specific to FAK (ESM Fig. 4b), without affecting cellular morphology (ESM Fig. 5), viability and growth rate (data not shown). We next studied the effect of FAK downregulation under the MF and MFI conditions with and without insulin stimulation. The level and phosphorylation of FAK in siRNA-transfected cells remained downregulated under all the culture conditions (Fig. 3a, ESM Fig. 6). Next, we examined the effect of FAK silencing on insulin-stimulated glucose uptake in siRNA-transfected cells (C2siRNAFAK $\left.{ }^{\mathrm{wt}}\right)$ differentiated under the MF and MFI conditions (Fig. 3b). Basal and
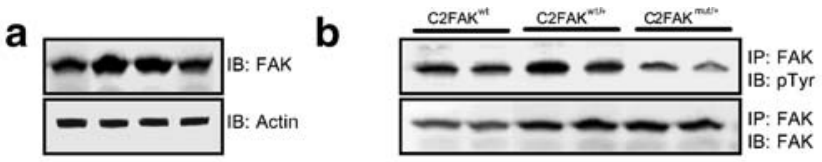

c
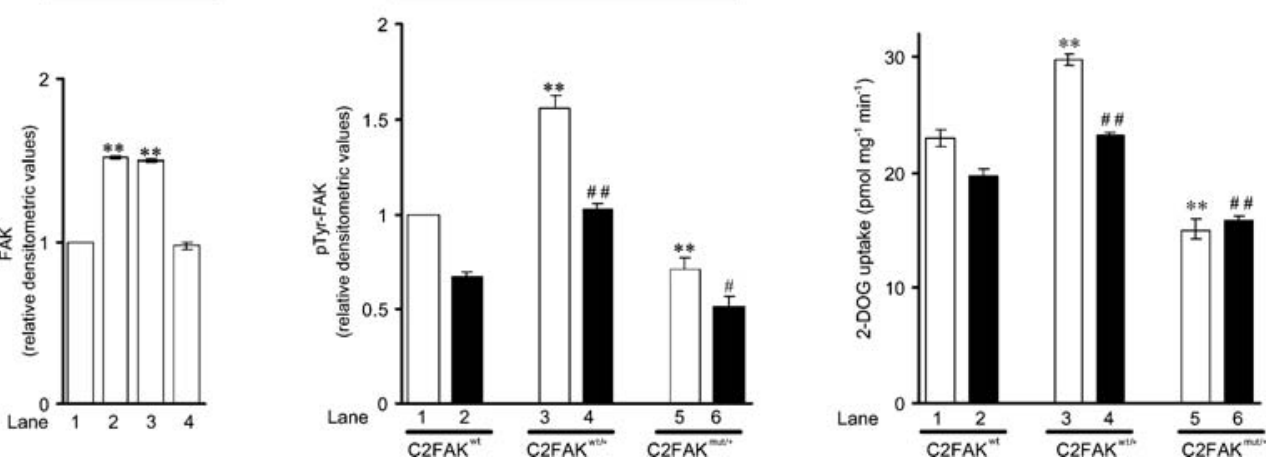

Fig. 2 Effect of modulation of FAK level on FAK tyrosine phosphorylation and glucose uptake. a $\mathrm{C} 2 \mathrm{C} 12$ cells were transfected with HA-tagged $\mathrm{FAK}^{\mathrm{wt}}$ and $\mathrm{FAK}^{\mathrm{mut}}$ containing vector pCDNA3.1, differentiated and lysed, and protein lysates (30 $\mu \mathrm{g}$ each) were subjected to western immunoblotting with anti-FAK antibody. Equal loading was confirmed by stripping and reprobing the blot with antiactin antibody. Bars represent relative densitometric values of FAK. Lane $1, \mathrm{C}_{2} \mathrm{FAK}^{\mathrm{wt}}$ cells; lane $2, \mathrm{C}_{2} \mathrm{FAK}^{\mathrm{wt} /+}$ cells; lane $3, \mathrm{C}^{\mathrm{F} A K^{\mathrm{mut} /+}}$ cells; lane 4, cells transfected with vector. Experiments were repeated three times. Values are mean \pm SE. $* * p<0.01$ compared with lane 1. b Transfected cells were differentiated in serum-free medium in the absence (MF) or chronic presence of $100 \mathrm{nmol} / 1$ insulin (MFI) for 3 days. Protein extracts $(200 \mu \mathrm{g}$ each) were immunoprecipitated with

anti-FAK antibody, subjected to western immunoblotting and probed with anti-phosphotyrosine or anti-FAK antibody. Bars represent relative densitometric values of pTyr-FAK. Experiments were repeated three times. Values are mean \pm SE. ${ }^{* *} p<0.01$ compared with lane 1 ; $\# \# p<0.01$ and $\# p<0.05$ compared with lane 2. c Cells differentiated in serum-free medium in the absence (MF) or chronic presence of insulin (MFI) for 3 days were stimulated with $100 \mathrm{nmol} / 1$ insulin for $15 \mathrm{~min}$. Uptake of 2-DOG was measured in $40 \mu \mathrm{g}$ cell lysates. Uptake was measured in duplicate. Data are pmol mg $\mathrm{min}^{-1}$. Experiments were repeated three times. Values are mean \pm SE. $* * p<0.01$ compared with lane 1, \#\#p<0.01 compared with lane 2. Open bars, MF; filled bars, MFI. IP, immunoprecipitated; $I B$, immunoblotted 

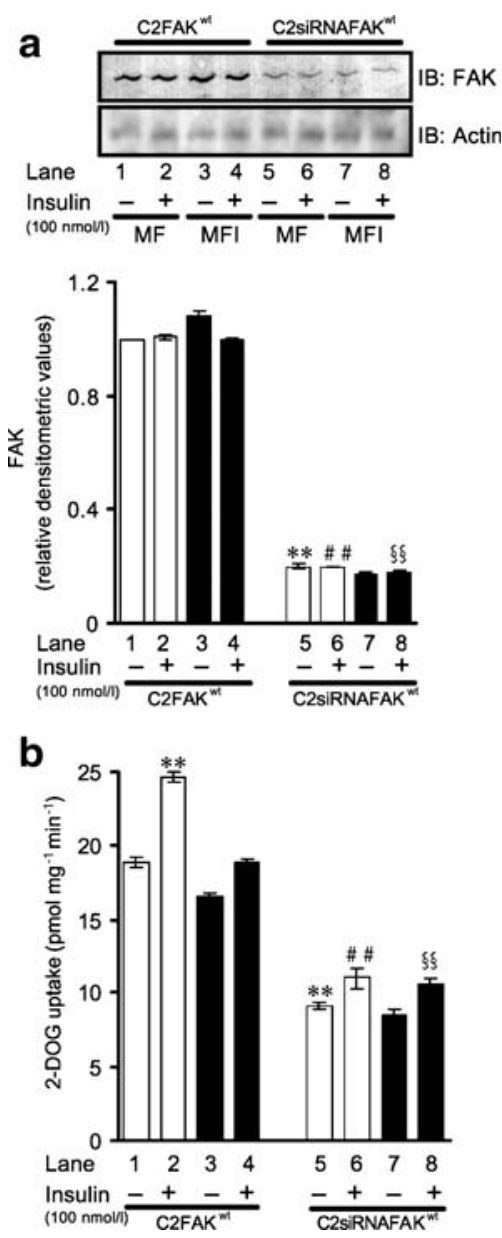

Fig. 3 Effect of FAK downregulation on glucose uptake. a Cells transfected with siRNA against FAK were differentiated under MF or MFI media with $(+)$ or without $(-)$ insulin $(100 \mathrm{nmol} / \mathrm{l})$ stimulation. Lysates were subjected to western immunoblotting and probed with antiFAK antibody. Blots were stripped and again probed with anti-actin antibody. Bar represents relative densitometric values of FAK expression. Experiments were repeated three times. Values are mean \pm SE. ${ }^{* *} p<0.01$ compared with lane $1 ;{ }^{\# \#} p<0.01$ compared with lane 2; $\S \S_{p}<0.01$ compared with lane 4 . b Effect of FAK knock-down on glucose uptake. siRNA-transfected cells were differentiated under MF and MFI conditions and analysed for insulin-mediated glucose uptake. Uptake was measured in duplicate. Data are shown as pmol mg ${ }^{-1} \mathrm{~min}^{-1}$. Experiments were repeated three times. Values are mean \pm SE. ${ }^{*} p<00.01$ compared with lane $1 ;{ }^{\# \#} p<0.01$ compared with lane $2 ;{ }^{\S} p<0.01$ compared with lane 4. Open bars, MF; filled bars, MFI

insulin-stimulated glucose uptake were reduced by $52.1 \pm$ 0.23 and $55.2 \pm 0.70 \%$ in C2siRNAFAK ${ }^{\mathrm{wt}}$ cells compared with $\mathrm{C}_{2} \mathrm{FAK}^{\mathrm{wt}}$ cells, respectively (Fig. $3 \mathrm{~b}$, lane 5 vs lane 1 , $p<0.01$; lane 6 vs lane $2, p<0.01$ ). Similar decreases were observed under the insulin-resistant condition. No change in insulin-stimulated glucose uptake was observed in cells transfected with non-specific siRNA (ESM Fig. 7). siRNA knock-down further supports the idea that elimination of FAK decreases cellular glucose uptake, which might be a consequence of impaired insulin signalling. To further substantiate our results, FAK was silenced in L6E9 cells, which are known to have a greater concentration of glucose transporter than $\mathrm{C} 2 \mathrm{C} 12$ cells, and the cells were used in experiments similar to those described above. Basal and insulin-stimulated glucose uptake was both substantially reduced in FAK-silenced L6E9 cells (L6siRNAFAK ${ }^{\mathrm{wt}}$ ) compared with non-silenced wild-type cells (L6FAK ${ }^{\mathrm{wt}}$ ) (ESM Fig. 8). The data suggest that the FAK is necessary for insulin-stimulated glucose uptake in L6E9 cells, as observed in the $\mathrm{C} 2 \mathrm{C} 12$ cell line.

We next examined the potential molecular mechanisms that might underlie the protection from insulin resistance conferred by an increased level of FAK and corresponding tyrosine phosphorylation. The possible mechanisms include increased insulin-mediated activation of the IR and/or its downstream molecules. Therefore, we examined IR- $\beta$ tyrosine phosphorylation and production in $\mathrm{C}_{2} \mathrm{FAK}^{\mathrm{wt}}$, $\mathrm{C}_{2} \mathrm{FAK}^{\mathrm{wt} /+}, \mathrm{C}_{2} \mathrm{FAK}^{\mathrm{mut} /+}$ and C2siRNAFAK ${ }^{\mathrm{wt}}$ cells under the MF and MFI conditions. No significant change in insulin-mediated activation or level of IR- $\beta$ due to modulation of FAK activation was observed (data not shown).

Previously, FAK was reported to interact with IRS-1 but not with IR [31-33]. Therefore, IRS-1 tyrosine phosphorylation and protein level in $\mathrm{C}_{2} \mathrm{FAK}^{\mathrm{wt}}, \mathrm{C}_{2} \mathrm{FAK}^{\mathrm{wt} /+}$ and $\mathrm{C}_{2} \mathrm{FAK}^{\mathrm{mut} /+}$ cells under MF and MFI conditions were examined. $\mathrm{C}_{2} \mathrm{FAK}^{\mathrm{wt} /+}$ cells in the MF condition showed increased $(92.8 \pm 0.05 \%)$ insulin-stimulated IRS-1 phosphorylation (Fig. $4 \mathrm{a}$, lane 4 vs lane $2, p<0.01$ ), whereas a decrease $(46.4 \pm 0.03 \%)$ was seen in $\mathrm{C} 2 \mathrm{FAK}^{\mathrm{mut} /+}$ cells (Fig. 4a, lane 6 vs lane $2, p<0.01$ ), in which phosphorylation was similar to that in insulin-resistant $\mathrm{C}_{2} \mathrm{FAK}^{\mathrm{wt}}$ cells (Fig. 4a, lane 6 vs lane 8). C2FAK ${ }^{\mathrm{wt} /+}$ cells under the MFI condition showed an $80.7 \pm 0.03 \%$ increase in insulinstimulated IRS-1 tyrosine phosphorylation (Fig. 4a, lane 10 vs lane $8, p<0.01$ ), and the level of phosphorylation was similar to that in C2FAK ${ }^{\mathrm{wt}}$ cells (Fig. 4a, lane 10 vs lane 2), whereas it decreased (by $24.9 \pm 0.01 \%$ ) in $\mathrm{C}_{2} \mathrm{FAK}^{\text {mut/+ }}$ cells (Fig. $4 \mathrm{a}$, lane 12 vs lane $8, p<0.01$ ). No significant change was observed in the level of IRS-1. To confirm these results, IRS-1 tyrosine phosphorylation was measured in C2siRNAFAK ${ }^{\mathrm{wt}}$ cells. Decreases in insulin-stimulated IRS-1 phosphorylation of $71.0 \pm 0.02 \%$ in the MF condition and $41.5 \pm 0.02 \%$ in the MFI condition (Fig. $4 \mathrm{~b}$, lane 6 vs lane 2, $p<0.01$; lane 8 vs lane $4, p<0.01$ ) were observed; these results were similar to those observed in C2FAK ${ }^{\mathrm{mut} /+}$ cells. The data therefore suggest that at least one of the ways in which FAK regulates insulin resistance in $\mathrm{C} 2 \mathrm{C} 12$ skeletal muscle is through IRS-1 tyrosine phosphorylation. FAK functions upstream of IRS-1, as inhibition of FAK abrogates IRS-1 phosphorylation.

To explore the role(s) of FAK in regulating downstream molecules, IRS-1-associated PI3K activity was determined. In $\mathrm{C}_{2} \mathrm{FAK}^{\mathrm{wt} /+}$ cells, insulin-stimulated PI3K activity increased $1.7 \pm 0.29$-fold in the MF condition (Fig. 4c, lane 4 

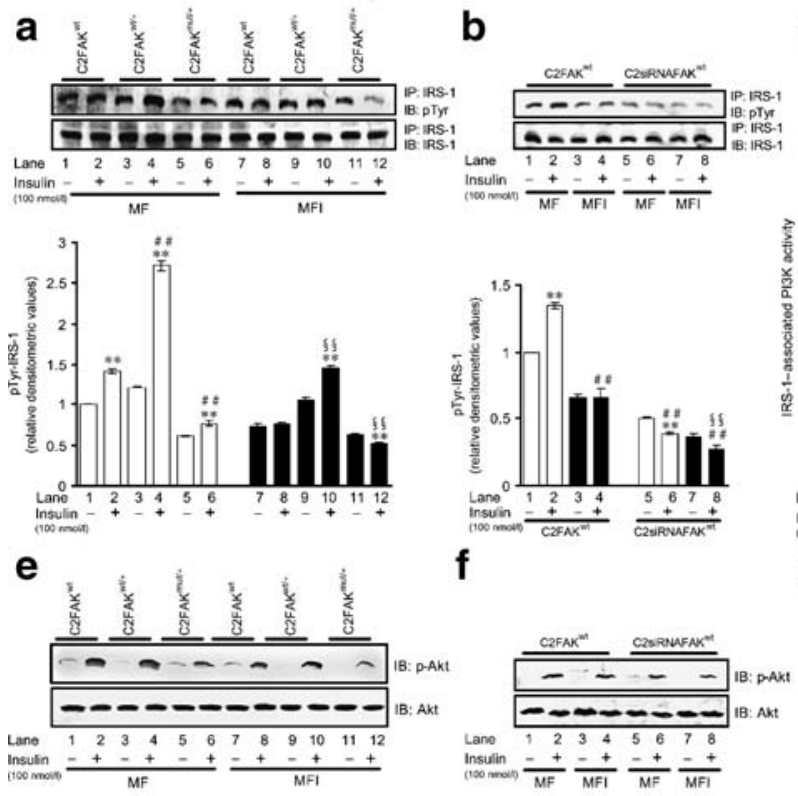

C

d

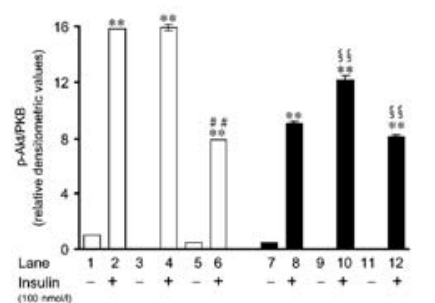

Fig. 4 Effect of modulation of FAK on insulin signalling. Transfected and untransfected cells were differentiated in serum-free medium in the absence (MF) or chronic presence of insulin (MFI) for 3 days and stimulated with or without insulin $(100 \mathrm{nmol} / \mathrm{l})$ for $10 \mathrm{~min}$. a Cell lysates $(500 \mu \mathrm{g})$ were immunoprecipitated with anti-IRS-1 antibody, subjected to western immunoblotting and probed with anti-phosphotyrosine antibody or anti-IRS-1 antibody. Bars represent relative densitometric values of pTyr-IRS-1 normalised to protein levels. Experiments were repeated three times. Values are mean \pm SE. ${ }^{* *} p<0.01$ compared with lane $1 ;{ }^{\# \#} p<0.01$ compared with lane $2 ;{ }^{\S}{ }^{\S} p<0.01$ compared with lane 8 . b siRNA-transfected myotubes were stimulated with or without insulin $(100 \mathrm{nmol} / \mathrm{l})$ for $10 \mathrm{~min}$ and lysed. Lysate $(500 \mu \mathrm{g})$ was immunoprecipitated with anti-IRS-1 antibody, subjected to western immunoblotting and probed with anti-phosphotyrosine or anti-IRS-1 antibody. Bars represent relative densitometric values of pTyr-IRS-1 normalised to protein levels. Experiments were repeated three times. Values are mean \pm SE. ${ }^{* *} p<0.01$ compared with lane $1 ;{ }^{\# \#} p<0.01$ compared with lane 2 ; $\S \S p<0.01$ compared with lane 4 . c Cell lysates $(500 \mu \mathrm{g})$ were immunoprecipitated with anti-IRS-1 antibody and PI3K activity was measured. Experiments were repeated three times. Values are mean $\pm \mathrm{SE}$. ${ }^{* *} p<0.01$ compared with lane $1 ;{ }^{\# \#} p<0.01$ compared with lane $2 ;{ }^{\S} p<<$ 0.01 compared with lane 8 . d siRNA-transfected myotubes were lysed, the lysate $(500 \mu \mathrm{g})$ was immunoprecipitated with anti-IRS-1 antibody, and PI3K activity were tested in the immunoprecipitates. Experiments were repeated three times. Values are mean \pm SE. $* * p<0.01$ compared with lane $1 ;{ }^{\# \#} p<0.01$ compared with lane $2 ;{ }^{\S} p<0.01$ compared with

vs lane $2, p<0.01$ ), whereas it decreased $2.18 \pm 0.08$-fold in

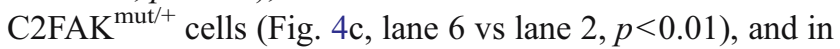
the mutant cells the PI3K activity was same as that of insulin-resistant $\mathrm{C}_{2} \mathrm{FAK}^{\mathrm{wt}}$ cells (Fig. 4c, lane 6 vs lane 8).

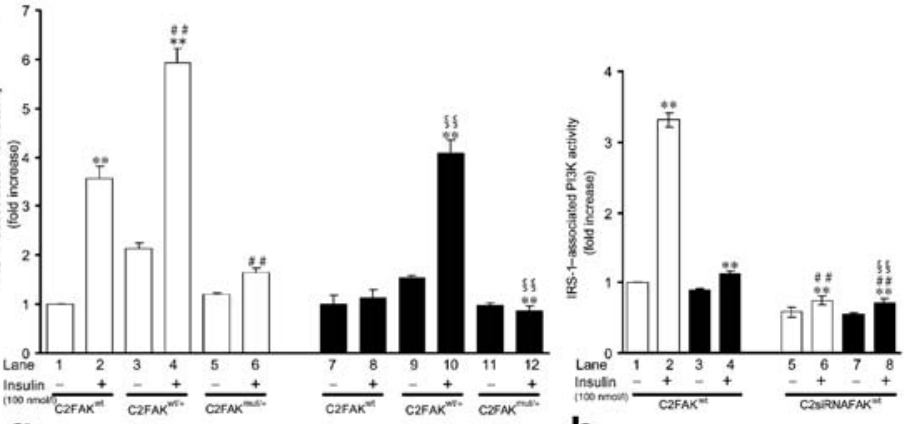

g

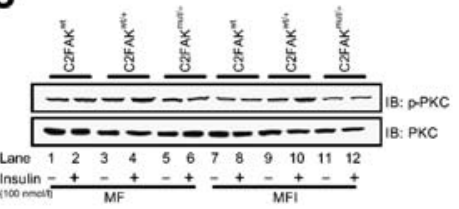

h

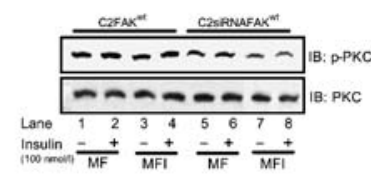

lane 4. e Cell lysates $(30 \mu \mathrm{g})$ were subjected to western immunoblotting and probed with anti-phospho Akt (Ser473) antibody or anti-Akt antibody. Bars represent relative densitometric values of pAkt (Ser473) normalised to protein levels. Experiments were repeated three times. Values are mean \pm SE. ${ }^{* *} p<0.01$ compared with lane 1 ; ${ }^{\#} p<0.01$ compared with lane 2 ; ${ }^{\S} p<0.01$ compared with lane 8 . f siRNAtransfected differentiated cells were lysed, and the lysates $(30 \mu \mathrm{g})$ were subjected to western immunoblotting and probed with anti-phospho Akt (Ser473) antibody or anti-Akt antibody. Bars represent relative densitometric values of pAkt (Ser473) normalised to protein levels. Experiments were repeated three times. Values are mean \pm SE. $* * p<0.01$ compared with lane $1 ;{ }^{\#} p<0.01$ compared with lane $2 ;{ }^{\S}{ }_{p}<0.01$ compared with lane 4 . g Cell lysates $(30 \mu \mathrm{g})$ were subjected to western immunoblotting and probed with anti-phospho pan-PKC antibody (pPKC) or anti-pan-PKC antibody. Bars represent relative densitometric values of $\mathrm{pPKC}$ normalised to protein levels. Experiments were repeated three times. Values are mean \pm SE. ${ }^{* *} p<0.01$ compared with lane $1 ;{ }^{\#} p<$ 0.01 compared with lane $2 ;{ }^{\S} p<<0.01$ compared with lane 8 . h siRNAtransfected differentiated cells were lysed, and the lysates $(30 \mu \mathrm{g})$ were subjected to western immunoblotting and probed with anti-phospho pan-PKC antibody and anti-pan-PKC antibody. Bars represent relative densitometric values of pPKC normalised to protein levels. Experiments were repeated three times. Values are mean \pm SE. $* * p<0.01$ compared with lane $1 ;{ }^{\#} p<0.01$ compared with lane $2 ;{ }^{\S} p<0.01$ compared with lane 4. Open bar, MF; filled bar, MFI. IP, immunoprecipitated; $I B$, immunoblotted

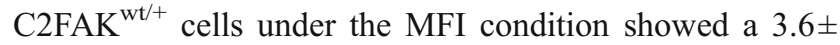
0.25 -fold increase in PI3K activity (Fig. $4 \mathrm{c}$ lane 10 vs lane $8, p<0.01)$, and the extent of activation was same as that of insulin-sensitive $\mathrm{C}_{2} \mathrm{FAK}^{\mathrm{wt}}$ cells (Fig. 4c, lane 10 vs lane 2). 

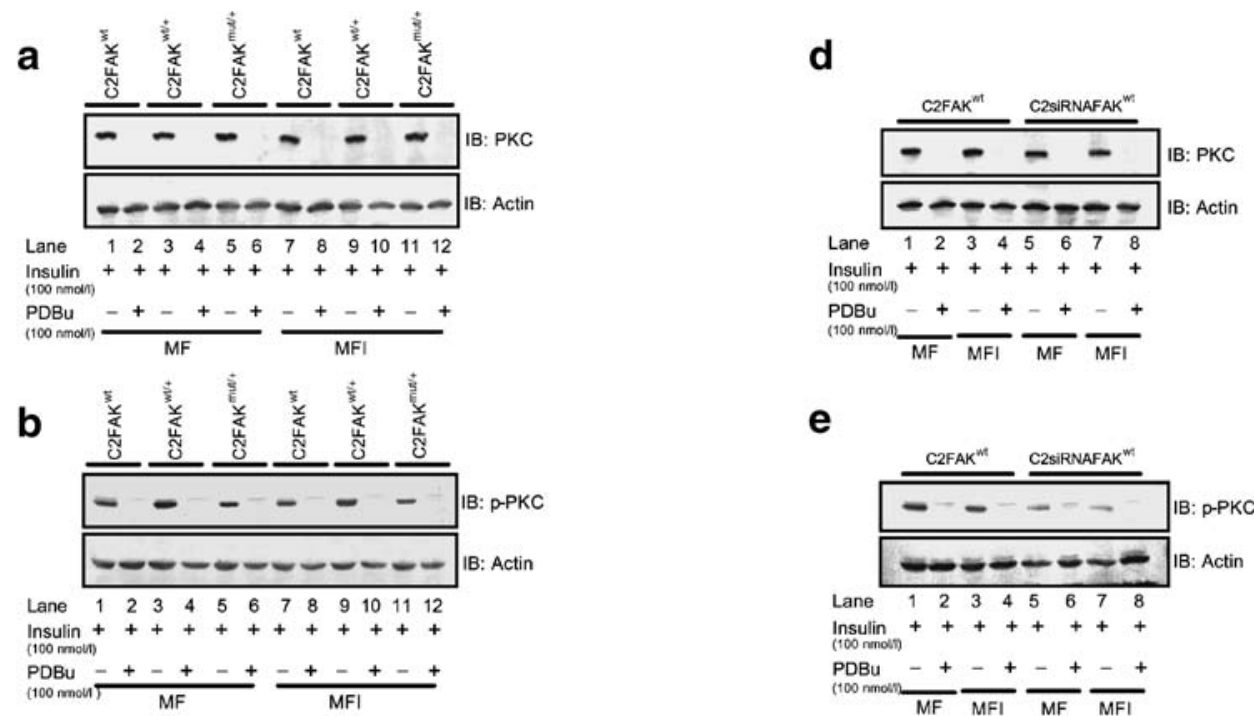

e

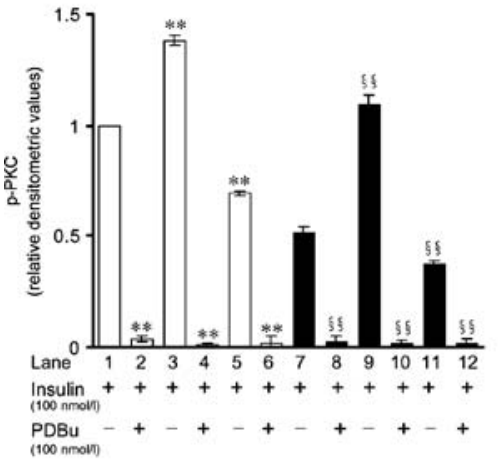

C
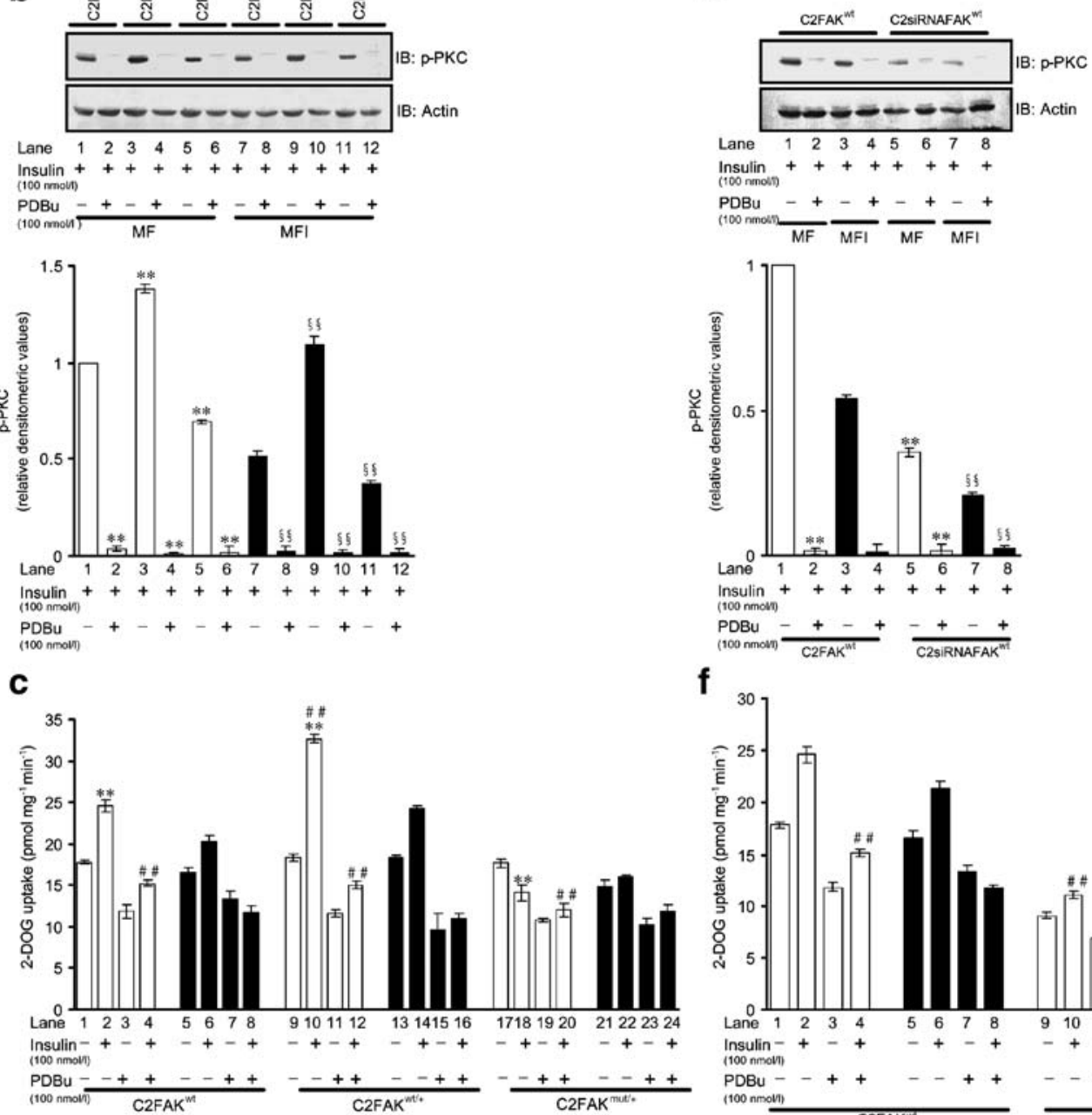

f

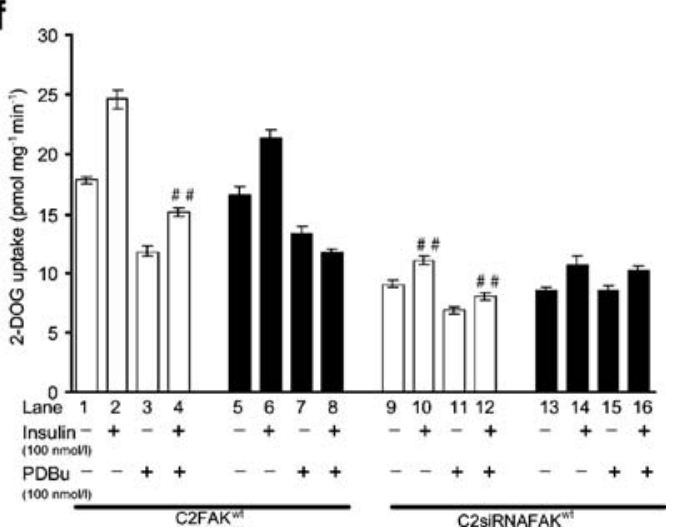

Fig. 5 Effect of PKC inhibition on FAK-mediated glucose uptake. Transfected and untransfected cells were differentiated in serum-free medium in the absence (MF) or chronic presence (MFI) of insulin and $\mathrm{PDBu}(100 \mathrm{nmol} / \mathrm{l})$ for 3 days, and stimulated with or without insulin $(100 \mathrm{nmol} / \mathrm{l})$ for $10 \mathrm{~min}$. a, d Cell lysates $(30 \mu \mathrm{g})$ of insulin-stimulated cells differentiated in the presence of PDBu were subjected to western immunoblotting and probed with anti-pan-PKC antibody, stripped and reprobed with anti-actin antibody. b Cell lysates $(30 \mu \mathrm{g})$ of insulinstimulated cells differentiated in presence of PDBu were subjected to western immunoblotting, probed with anti-phospho pan-PKC antibody (pPKC), stripped and reprobed with anti-actin antibody. Experiments were repeated three times. Values are mean \pm SE. $* * p<0.01$ compared with lane $1 ;{ }^{\#} p<0.01$ compared with lane $2 ;{ }^{\S} p<<0.01$ compared with

lane 8. c, f Cells differentiated in serum-free medium in the absence (MF) or chronic presence of insulin (MFI) and PDBu (100 nmol/l) for 3 days were stimulated with $100 \mathrm{nmol} / \mathrm{l}$ insulin for $15 \mathrm{~min}$. Uptake of 2-DOG was measured in $40 \mu \mathrm{g}$ cell lysates. Experiments were repeated three times. Values are mean \pm SE. $* * p<0.01$ compared with lane $1 ;{ }^{\# \#} p<0.01$ compared with lane 2. e Cell lysates $(30 \mu \mathrm{g})$ of insulin-stimulated cells differentiated in the presence of PDBu were subjected to western immunoblotting, probed with anti-phospho panPKC antibody (pPKC), stripped and reprobed with anti-actin antibody. Experiments were repeated three times. Values are mean $\pm \mathrm{SE}$. ${ }^{* *} p<0.01$ compared with lane $1 ;{ }^{\#} p<0.01$ compared with lane 2; ${ }^{\S} p<0.01$ compared with lane 4. Open bars, MF; filled bars, MFI 
Insulin-stimulated IRS-1-associated PI3K activity was unaltered in $\mathrm{C} 2 \mathrm{FAK}^{\mathrm{mut} /+}$ cells under the MFI condition (Fig. 4c, lane 12 vs lane 11 ), but decreased $4.4 \pm 0.01$-fold and 1.2 \pm 0.01 -fold under the MF and MFI conditions, respectively (Fig. 4d, lane 6 vs lane 2, $p<0.01$; lane 8 vs lane $4, p<0.01$ ) in C2siRNAFAK ${ }^{\mathrm{wt}}$ cells.

PI3K activates several PIP3-dependent serine/threonine kinases, e.g. Akt (also known as protein kinase B [PKB]) and protein kinase $\mathrm{C}(\mathrm{PKC})[34,35]$. Therefore, insulinstimulated activation, if any, of Akt was examined in all the cell lines (Fig. 4e). No additional insulin-stimulated effect of Akt phosphorylation (Ser473) was observed in

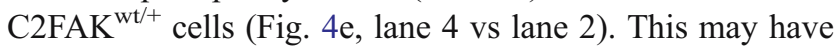
been due to saturable activation of Akt. Although under the insulin-resistant condition $\mathrm{C} 2 \mathrm{FAK}^{\mathrm{wt} /+}$ cells showed additional insulin-stimulated Akt phosphorylation, the extent of activation was not equivalent to that seen in insulinsensitive $\mathrm{C}^{2} \mathrm{FAK}^{\mathrm{wt}}$ cells (Fig. 4e, lane 10 vs lane 2). $\mathrm{C}_{2} \mathrm{FAK}^{\mathrm{mut} /+}$ cells displayed decreased Akt activation in both the MF and the MFI condition (Fig. 4e, lane 6 vs lane $2, p<0.01$; lane 12 vs lane $8, p<0.01)$. Similar decreases were observed in C2siRNAFAK ${ }^{\mathrm{wt}}$ cells $(66.2 \pm 0.2$ and $58 \pm$ $0.13 \%$ in the MF and MFI conditions, respectively) (Fig. 4f, lane 6 vs lane $2, p<0.01$; lane 8 vs lane $4, p<0.01$ ). This indicates possible signal divergence under the insulinresistant condition.

PKC is reported to regulate glucose uptake downstream of PI3K [34, 35]. Therefore, insulin-stimulated activation of PKC, if any, was tested in all the cell lines by probing with anti-phospho pan-PKC antibody. Insulin-stimulated PKC phosphorylation of $\mathrm{C}^{2} \mathrm{FAK}^{\mathrm{wt} /+}$ cells increased (by $21.4 \pm 0.05 \%$ ) under the MF condition (Fig. $4 \mathrm{~g}$, lane 4 vs lane $2, p<0.01$ ) but decreased (by $37.4 \pm 0.03 \%$ ) in $\mathrm{C}_{2} \mathrm{FAK}^{\mathrm{mut} / \mathrm{t}}$ cells (Fig. $4 \mathrm{~g}$, lane 6 vs lane $2, p<0.01$ ), and the level of activation was similar to that in insulin-resistant $\mathrm{C}_{2} \mathrm{FAK}^{\mathrm{wt}}$ cells (Fig. 4g, lane 6 vs lane 8). Insulinstimulated PKC phosphorylation increased $(76.3 \pm 0.03 \%)$ in $\mathrm{C} 2 \mathrm{FAK}^{\mathrm{wt} /+}$ cells under the MFI condition (Fig. $4 \mathrm{~g}$, lane 10 vs lane $8, p<0.01$ ), and the extent of activation was as observed in insulin-sensitive C2FAK ${ }^{\mathrm{wt}}$ cells (Fig. 4g, lane 10 vs lane 2), whereas it was further decreased (37.5 \pm $0.01 \%$ ) in $\mathrm{C}^{2} \mathrm{FAK}^{\mathrm{mut} /+}$ cells (Fig. $4 \mathrm{~g}$, lane 12 vs lane 8, $p<0.01$ ) without affecting its protein level (Fig. 4g). PKC phosphorylation of C2siRNAFAK ${ }^{\mathrm{wt}}$ cells decreased by $62.6 \pm 0.02$ and $56 \pm 0.01 \%$ under the MF and MFI conditions, respectively (Fig. 4h, lane 6 vs lane $2, p<0.01$ and lane 8 vs lane $4, p<0.01$ ) without altering the protein level. The data confirm the involvement of PKC and suggest its
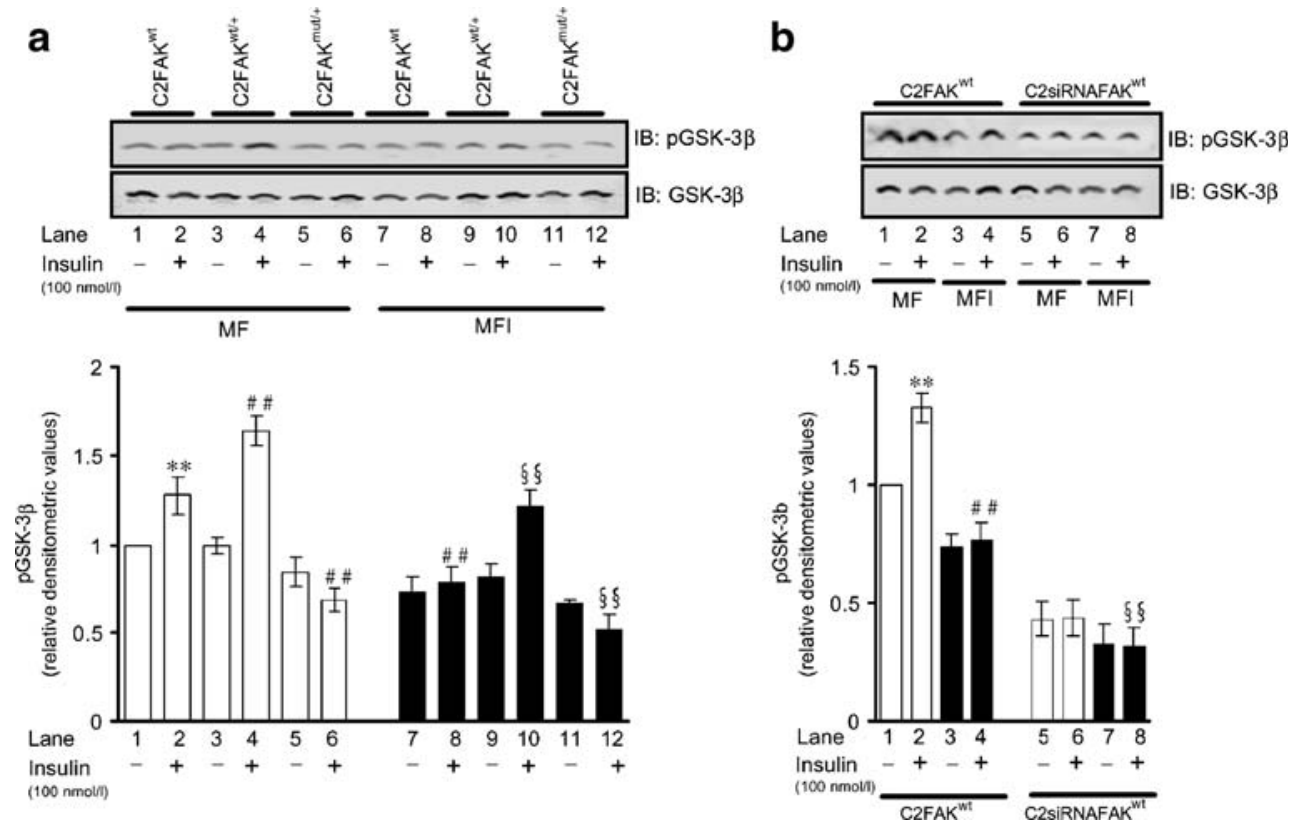

Fig. 6 Effect of modulation of FAK on GSK-3 3 . Transfected and untransfected cells were differentiated in serum-free medium in the absence (MF) or chronic presence (MFI) of insulin for 3 days, and stimulated with or without insulin $(100 \mathrm{nmol} / \mathrm{l})$ for $10 \mathrm{~min}$. a Cell lysates $(30 \mu \mathrm{g})$ were subjected to western immunoblotting and probed with anti-phospho (Ser) GSK-3 $\beta$ antibody or anti-GSK-3 $\beta$ antibody. Bars represent relative densitometric values of pGSK- $3 \beta$ normalised to protein levels. Experiments were repeated three times. Values are mean \pm SE. ${ }^{* *} p<0.01$ compared with lane $1{ }^{* \#} p<0.01$ compared with

lane $2 ;{ }^{\S} p<0.01$ compared with 8 . b siRNA-transfected myotubes were lysed, and the lysates $(30 \mu \mathrm{g})$ were subjected to western immunoblotting and probed with anti-phospho (Ser) GSK-3 $\beta$ antibody or anti-GSK-3 $\beta$ antibody. Bars represent relative densitometric values of pGSK-3 $\beta$ normalised to protein levels. Experiments were repeated three times. Values are mean \pm SE. ${ }^{* *} p<0.01$ compared with lane 1 ; ${ }^{\# \#} p<0.01$ compared with lane $2 ;{ }^{\S \S} p<0.01$ compared with lane 4 . Open bars, MF; filled bars, MFI 
possible involvement in signal divergence in FAK-mediated insulin signalling.

To evaluate the contribution of PKC to glucose uptake, we downregulated the level of PKC by differentiating $\mathrm{C} 2 \mathrm{FAK}^{\mathrm{wt}}, \mathrm{C}^{2} \mathrm{FAK}^{\mathrm{wt} /+}$ and $\mathrm{C} 2 \mathrm{FAK}^{\mathrm{mut} /+}$ cells under prolonged exposure (3 days) to $100 \mathrm{nmol} / 1$ phorbol 12,13dibutyrate (PDBu) $[4,36]$. PKC protein level (Fig. 5a) and phosphorylation (Fig. 5b) were completely inhibited under all the conditions examined. A significant decrease in insulin-stimulated glucose uptake was observed in all the cell lines treated with PDBu (Fig. 5c). Similar effects on PKC level/phosphorylation (Fig. 5d,e) and glucose uptake (Fig. 5f) were observed in C2siRNAFAK ${ }^{\mathrm{wt}}$ cells treated with PDBu. The data suggest that PKC is the downstream molecule responsible for FAK-mediated glucose uptake.

FAK was previously reported to regulate the activity of GSK-3 $\beta$ (a regulatory enzyme upstream of glycogen synthase) in hepatocytes, [7, 13]. To determine whether the observed effect of an increased level of FAK was accompanied by GSK-3 $\beta$ activation, insulin-stimulated Ser-9 phosphorylation of GSK-3 $\beta$ was examined. C2FAK ${ }^{\mathrm{wt} /+}$ cells increased insulin-stimulated GSK-3 $\beta$ phosphorylation under the MF condition (by $27.8 \pm 0.05 \%$; Fig. $6 \mathrm{a}$, lane 4 vs lane 2, $p<0.01$ ), whereas phosphorylation was decreased in $\mathrm{C}_{2} \mathrm{FAK}^{\mathrm{mut} /+}$ cells (by $32.4 \pm 0.03 \%$; Fig. $6 \mathrm{a}$, lane 6 vs lane 2, $p<0.01)$ compared with insulin-resistant $\mathrm{C} 2 \mathrm{FAK}^{\mathrm{wt}}$ cells (Fig. 6a, lane 6 vs lane 8 ). C2FAK ${ }^{\mathrm{wt} /+}$ cells showed increased (by $49.3 \pm 0.03 \%$ ) GSK- $3 \beta$ phosphorylation under the MFI condition (Fig. 6a, lane 10 vs lane $8, p<0.01$ ), and the level of phosphorylation was similar to that observed in insulin-

a
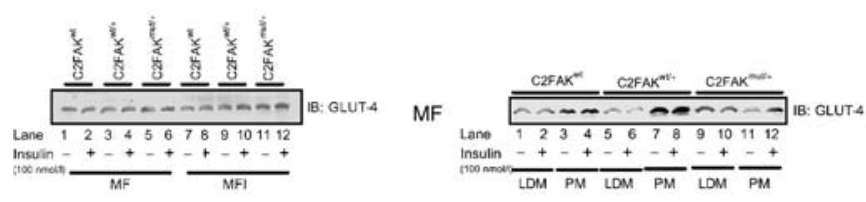

b

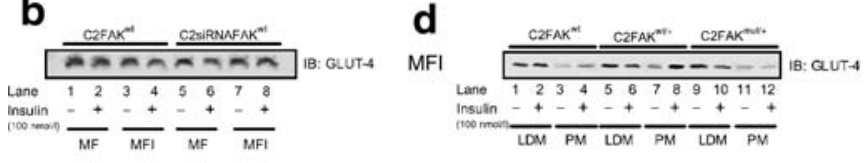

Fig. 7 Effect of modulation of FAK levels on GLUT4 translocation. Transfected and untransfected cells were differentiated in serum-free medium in the absence (MF) or chronic presence of insulin (MFI) for 3 days, then stimulated with or without insulin $(100 \mathrm{nmol} / \mathrm{l})$ for $10 \mathrm{~min}$. a, b Cell lysates $(50 \mu \mathrm{g})$ of insulin-stimulated differentiated cells were subjected to western immunoblotting and probed with antiGLUT4 antibody. $\mathbf{c}-\mathbf{e}$ Cells were differentiated in MF or MFI medium sensitive $\mathrm{C}_{2} \mathrm{FAK}^{\mathrm{wt}}$ cells (Fig. 6a, lane 10 vs lane 2), whereas it was further decreased (by $21.5 \pm 0.01 \%$ ) in $\mathrm{C}_{2} \mathrm{FAK}^{\mathrm{mut} /+}$ cells (Fig. 6a, lane 12 vs lane $8, p<0.01$ ). An acute decrease in GSK-3 $\beta$ phosphorylation was observed in C2siRNAFAK $^{\mathrm{wt}}$ cells under the MF and MFI conditions (Fig. 6b, lane 6 vs lane $2, p<0.01$ and lane 8 vs lane $4, p<0.01$ ). No change in GSK-3 $\beta$ level was observed under any condition. The data suggest anabolism between enhanced glucose uptake and glycogen synthesis as a result of increased GSK-3 $\beta$ phosphorylation due to FAK overproduction.

Since no change in the level of GLUT4 was observed in any of the cell lines under any condition (Fig. 7a,b), insulin-stimulated translocation of GLUT4 was examined in subcellular fractions (LDM and plasma membrane). We observed a $32.0 \pm 0.12 \%$ increase in GLUT4 translocation to the plasma membrane fraction of $\mathrm{C}_{2} \mathrm{FAK}^{\mathrm{wt} /+}$ cells under the MF condition (Fig. 7c, lanes 7 and 8 vs lanes 3 and 4), indicating enhanced insulin-stimulated GLUT4 translocation due to an increased level of FAK. In contrast, GLUT4 molecules remained in the LDM fraction in insulinsensitive $\mathrm{C}_{2} \mathrm{FAK}^{\mathrm{mut} /+}$ cells (Fig. 7c, lanes 9 and $10 \mathrm{vs}$ lanes 1 and 2). Under the MFI condition, maximum translocation was observed in $\mathrm{C} 2 \mathrm{FAK}^{\mathrm{wt} /+}$ cells (Fig. $7 \mathrm{~d}$, lanes 7 and 8 vs lanes 3 and 4) and almost no translocation was observed in $\mathrm{C} 2 \mathrm{FAK}^{\mathrm{mut} /+}$ cells (Fig. 7d, lanes 11 and 12 vs lanes 1 and 2). Insulin-stimulated incremental GLUT4 translocation was significantly impaired in C2siRNAFAK ${ }^{\mathrm{wt}}$ cells compared with $\mathrm{C} 2 \mathrm{FAK}^{\mathrm{wt}}$. In contrast to $\mathrm{C} 2 \mathrm{FAK}{ }^{\mathrm{wt}}$ cells, the maximum number of GLUT4 molecules in C2siRNAFAK ${ }^{\mathrm{wt}}$ cells remained in the LDM fraction under

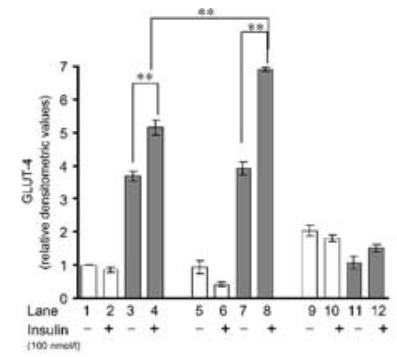

e
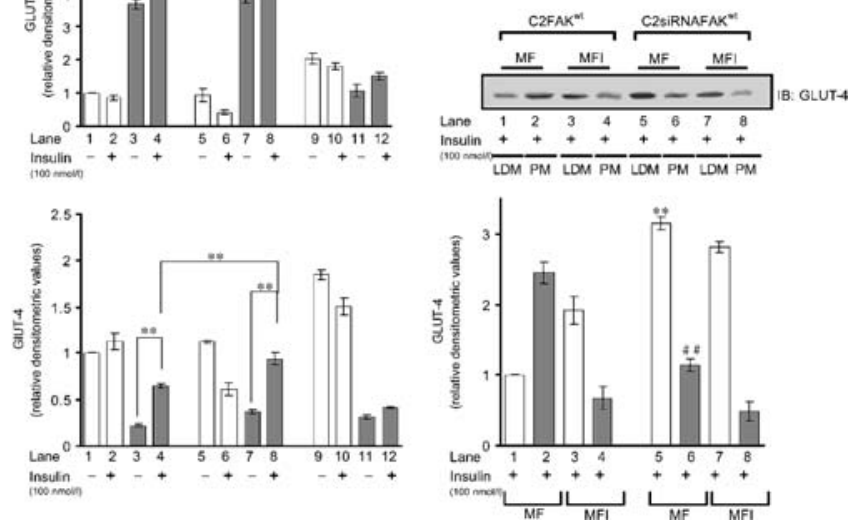

and then stimulated with $100 \mathrm{nmol} / 1$ insulin for $10 \mathrm{~min}$. The LDM and plasma membrane fractions were isolated, subjected to western immunoblotting and probed with anti-GLUT4 antibody. Experiments were repeated three times. Values are mean \pm SE. $* * p<0.01$ compared with lane 1; ${ }^{\#} p<0.01$ compared with lane 2. Open bars, LDM fraction; filled bars, plasma membrane fraction. IP, immunoprecipitated, $I B$, immunoblotted 
the MF as well as under the MFI condition (Fig. 7e, lane 5 vs lane 1 and lane 7 vs lane 3). However, in the plasma membrane fraction there was a significant decrease in the translocation of GLUT4 in C2siRNAFAK ${ }^{\mathrm{wt}}$ cells compared with $\mathrm{C} 2 \mathrm{FAK}^{\mathrm{wt}}$ cells, which was further decreased under the MFI condition (Fig. 7e, lane 6 vs lane 2 and lane 8 vs lane 4). These results confirm the regulation of glucose uptake via GLUT4 translocation in skeletal muscle cells in vitro by FAK.

\section{Discussion}

In the present study a direct correlation was observed between FAK protein level/phosphorylation and glucose uptake in the presence of insulin, suggesting insulindependent regulation of insulin resistance in $\mathrm{C} 2 \mathrm{C} 12$ skeletal muscle cells by FAK. Huang et al. [18] reported that downregulation of FAK affects only insulin-stimulated glucose uptake, unlike the observations in our study (Fig. 3b). One of the possible explanations for this could be that Huang et al. reported glucose uptake when there was $53 \%$ downregulation in the level of FAK, leaving approximately $47 \%$ of the endogenous FAK available, whereas in our study $85 \%$ of the FAK was downregulated, thus eliminating any significant contribution of the endogenous protein. Under our experimental conditions, the mechanism of FAK-mediated regulation of insulin resistance could be the interaction of FAK with unidentified substrate(s) that becomes activated only in the presence of insulin and is necessary for the interaction between FAK and insulin signalling molecules. The observed increase in tyrosine phosphorylation in the basal condition of overexpressed FAK might be due to activation by other stimuli.

Like us, Annabi et al. [31] and Huang et al. [14] also observed no interaction between FAK and the IR in their studies, using $\mathrm{CHO}$ and HepG2 cells. However, we observed that up- or downregulation of FAK activity correspondingly affected insulin-stimulated glucose uptake via the IRS-1/PI3K pathway. Therefore, our results indicate that FAK regulates insulin signalling upstream of IRS-1 and then regulates the cascade downstream via PI3K. Insulin signalling without involving the IR, via IRS-1, has been reported previously in other non-receptor tyrosine kinases, pp59Lyn in 3T3-adipocytes [37]. FAK is also reported to interact with cytosolic tyrosine kinase $\mathrm{Src}$, which can regulate IRS-1 tyrosine phosphorylation in $\mathrm{CHO}$ cells [33]. In human embryo kidney cells, Lebrun et al. [33] have reported that FAK can phosphorylate IRS-1 without the participation of Src.

In our study, the mechanism whereby mutant FAK inhibits the ability of insulin to induce phosphorylation of Akt remains unclear. It is possible that endogenous FAK interacts with unidentified protein(s) necessary for interaction with Akt. Mutant FAK possibly exerts a dominant negative effect on endogenous FAK. A similar dissociation between these two proteins has been reported previously in hepatocytes [14]. However, an increased level of FAK ${ }^{\mathrm{wt}} \mathrm{did}$ not restore Akt phosphorylation under insulin-resistant conditions even though tyrosine phosphorylation of IRS-1 and PI3K activation was restored. A possible explanation includes additional regulation of Akt independently of PI3K in the insulin-resistant condition. Lin et al. [38] found that PKC activator decreased the ability of insulin to phosphorylate both Akt and GSK-3 $\beta$ in rat skeletal muscle, whereas PI3K activation was unaffected.

Decreased glucose uptake irrespective of an increased or decreased level of FAK under conditions of PKC inhibition indicates a markedly smaller contribution of Akt. Therefore, in the insulin-resistant condition the signal travels mainly through activated PI3K to PKC rather than to Akt. Earlier reports have suggested that phosphatidylinositol (3,4,5)-triphosphate (PIP3) produced by PI3K, responsible for both Akt and PKC phosphorylation, has more affinity for PKC than Akt [34]. Moreover, in the insulin-resistant condition PKC downregulates Akt and this is unaccompanied by a change in PI3K activity in skeletal muscle cells [37]. Therefore, it is possible that FAK differentially regulates insulin signalling under normal and insulinresistant conditions. Sajan et al. [39] recently reported a differential role of the atypical PKC isoforms $\zeta$ and $\lambda$ in insulin-stimulated glucose transport. Regulation of GLUT4 translocation in skeletal muscle of high-fat-diet-fed rats by PKC $(\zeta / \lambda)$ has also been reported [40]. Therefore, there is a possibility of FAK-regulated activity of PKC $\zeta / \lambda$, or any other isoform(s), in regulating insulin resistance. Further studies are in progress to determine the specific isoform(s) that may be responsible for interacting with FAK to regulate the pathway.

It has been reported that modulation of FAK level in hepatocytes regulates glycogen synthesis [7, 14]. We also observed that up- or downregulation of FAK correspondingly phosphorylates GSK- $3 \beta$, implying the regulation of glycogen synthesis by FAK in these cells.

Kotliar and Pilch [41] observed that the increased level of GLUT4 fails to reconstitute insulin-stimulated glucose transporter in $\mathrm{C} 2 \mathrm{C} 12$ cells and postulated the requirement for additional gene(s) to form functional translocating vesicles. Microtubules have been reported to be required for the translocation of GLUT4 [18, 42-46]. FAK is required for the stabilisation of microtubules in fibroblasts [47] and its tyrosine phosphorylation is essential for the insulin-stimulated rearrangement of actin fibres in $\mathrm{CHO} / \mathrm{IR}$ cells [10]. Huang et al. [18] reported that FAK regulates insulin-mediated cytoskeletal rearrangement essential for normal glucose transport and glycogen synthesis. There- 
fore, the observed increase in glucose uptake as a result of increased FAK level with no change in expression in our study is possibly due to the enhanced recruitment of actin filament and microtubules responsible for the GLUT4 translocation. Further studies are in progress to demonstrate interaction between GLUT, microtubules and FAK.

In summary, the present study demonstrates a novel role for FAK as a positive regulator of the insulin signalling pathway, leading to glucose transport and insulin sensitisation. This conclusion is based on the following findings: (1) in the insulin-resistant condition FAK was always found to be less active; (2) downregulation of FAK activity resulted in impaired insulin signalling; (3) decreased glucose uptake was a consequence of impaired insulin signalling due to downregulation of FAK; and (4) increased level of FAK in the insulin-resistant condition reversed all the above-mentioned observations. The stimulatory effect of FAK on insulinstimulated glucose transport involves the IRS-1/PI3K/PKC arm of the insulin signalling pathway. Interestingly, IR and Akt do not seem to contribute to the pathway. Since an increase in FAK and its phosphorylation sensitises $\mathrm{C} 2 \mathrm{C} 12$ skeletal muscle cells to insulin stimulation of GLUT4 translocation and glucose transport, these results further support a role for an insulin-stimulated FAK/IRS-1/PI3K/ PKC signalling pathway as a physiologically important mediator of the action of insulin. Since increased levels of FAK leads to cellular insulin sensitisation, these results also raise the possibility that interfering with FAK production or activation may provide opportunities for developing new therapeutic strategies against insulin resistance. Chemical activators of FAK would be expected to act as insulin sensitisers, which could have beneficial effects in insulin resistance induced by hyperinsulinaemia. This opens up the possibility of new therapeutic intervention.

Acknowledgements We thank C. L. Kaul, formerly director of NIPER, for his keen interest in this study. We also thank P. Ramarao, director of NIPER and head of the Pharmacology Department, for providing us with rat muscle samples. We gratefully acknowledge D. Schlaepfer of the Scripps Research Institute, La Jolla, CA, USA for providing pcDNA3.1-HA-FAKwt and pcDNA3.1-HA-FAKmut plasmids as a kind gift. R. Singh is acknowledged for his assistance in the laboratory. B. Bisht is the recipient of a Senior Research Fellowship and H. L. Goel was the recipient of a Senior Research Fellowship from the Council of Scientific and Industrial Research, Government of India, New Delhi. This study was also supported by a grant from the Department of Biotechnology, Government of India, New Delhi to C. S. Dey (BT/HRD/34/04/2004, dated 30.4.2004; BT/PR3994/ MED/14/498/2003, dated 30 September 2004).

\section{References}

1. Parson JT (2003) Focal adhesion kinase: the first ten years. J Cell Sci 116:1409-1416
2. Zachary I (1997) Focal adhesion kinase. Int J Biochem Cell Biol 29:929-934

3. Goel HL, Dey CS (2002) Focal adhesion kinase tyrosine phosphorylation is associated with myogenesis and modulated by insulin. Cell Prolif 35:131-142

4. Goel HL, Dey CS (2000) PKC-regulated myogenesis is associated with increase in phosphorylation of FAK, cas and paxillin, formation of cas-crk complex and JNK activation. Differentiation 70:257-271

5. Goel HL, Dey CS (2002) Insulin stimulates spreading of skeletal muscle cells involving the activation of focal adhesion kinase, phosphatidylinositol 3-kinase and extracellular signal regulated kinase. J Cell Physiol 193:187-198

6. Goel HL, Dey CS (2002) Role of protein kinase C during insulin mediated skeletal muscle cell spreading. J Muscle Res Cell Motil 23:269-277

7. Bianchi M, De Lucchini S, Marin O, Turner DL, Hanks SK, VillaMoruzzi E (2005) Regulation of FAK Ser-722 phosphorylation and kinase activity by GSK3 and PP1 during cell spreading and migration. Biochem J 391:359-370

8. Baron V, Calleja V, Ferrari P, Alengrin F, van Obberghen E (1998) p125Fak focal adhesion kinase is a substrate for the insulin and insulin-like growth factor-I tyrosine kinase receptors. J Biol Chem 273:162-7168

9. Tobe K, Sabe H, Yamamoto T et al (1996) Csk enhances insulinstimulated dephosphorylation of focal adhesion proteins. Mol Cell Biol 16:4765-4772

10. Knight JB, Yamauchi K, Pessin JE (1995) Divergent insulin and platelet-derived growth factor regulation of focal adhesion kinase (pp125FAK) tyrosine phosphorylation and rearrangement of actin stress fibers. J Biol Chem 270:10199-10203

11. Yujiri T, Nawata R, Takahashi T, Sato Y, Tanizawa Y, Kitamura T, Oka Y (2003) MEK kinase interacts with focal adhesion kinase and regulates insulin receptor substrate-1 expression. J Biol Chem 278:3846-3851

12. Wang Q, Bilan PJ, Klip A (1998) Opposite effects of insulin on focal adhesion proteins in 3T3-L1 adipocytes and in cells overexpressing the insulin receptor. Mol Biol Cell 9:3057-3069

13. Cheung AT, Wang J, Ree D, Kolls JK, Bryer-Ash M (2000) Tumor necrosis factor $\alpha$ induces hepatic insulin resistance in obese zucker (fa/fa) rats via interaction of leukocyte antigen related tyrosine phosphatase with focal adhesion kinase. Diabetes 49:810-819

14. Huang D, Cheung AT, Parsons JT, Bryer-Ash M (2002) Focal adhesion kinase (FAK) regulates insulin-stimulated glycogen synthesis in hepatocytes. J Biol Chem 227:18151-18160

15. Guilherme A, Torres K, Czech MP (1998) Cross-talk between insulin receptor and integrin $\alpha 5 \beta 1$ signaling pathways. J Biol Chem 273:22899-22903

16. Eliceiri BP (2001) Integrins and growth factor receptor crosstalk. Circ Res 89:1104-1110

17. Turner CE (2000) Paxillin and focal adhesion signaling. Nat Cell Biol 2:E231-E236

18. Huang D, Kohe M, Ilic D, Bryer-Ash M (2006) Reduced expression of focal adhesion kinase disrupts insulin action in skeletal muscle cells. Endocrinology 147:3333-3343

19. Kumar N, Dey CS (2003) Development of insulin resistance and reversal by thiazolidinediones in $\mathrm{C} 2 \mathrm{C} 12$ skeletal muscle cells. Biochem Pharmacol 65:249-257

20. Kumar N, Dey CS (2002) Metformin enhances insulin signaling in insulin-dependent and -independent pathways in insulinresistant muscle cells. Br J Pharmacol 137:329-336

21. Kumar N, Dey CS (2002) Gliclazide increases insulin receptor tyrosine phosphorylation but not $\mathrm{p} 38$ phosphorylation in insulin-resistant skeletal muscle cells. J Exp Biol 205: 3739-3746 
22. Verma NK, Singh J, Dey CS (2004) PPAR- $\gamma$ expression modulates insulin sensitivity in $\mathrm{C} 2 \mathrm{C} 12$ skeletal muscle cells. $\mathrm{Br}$ J Pharmacol 143:1006-1013

23. Michael LF, Wu Z, Cheatham RB et al (2001) Restoration of insulin-sensitive glucose transporter (GLUT4) gene expression in muscle cells by the transcriptional coactivator PGC-1. Proc Natl Acad Sci USA 98:3820-3825

24. Srinivasan K, Patole PS, Ramarao P (2004) Reversal of glucose intolerance by pioglitazone in high fat diet fed rats. Methods Find Exp Clin Pharmacol 26:327-333

25. Ghatta S, Ramarao P (2004) Increased contractile responses to 5-hydroxytrypamine and angiotensin II in high fat diet fed rat thoracic aorta. Lipids Health Dis 3:1-6

26. Sentinelli F, Filippi E, Cavallo MG, Romeo S, Fanelli M, Baroni MG (2006) The G972R variant of the insulin receptor substrate-1 gene impairs insulin signaling and cell differentiation in 3T3L1 adipocytes: treatment with a PPARgamma agonist restores normal cell signaling and differentiation. J Endocrinol 188:271-285

27. Kobayashi T, Hayashi Y, Taguchi K, Matsumoto T, Kamata K (2006) ANG II enhances contractile responses via PI3-kinase p110b pathway in aortas from diabetic rats with systemic hyperinsulinemia. Am J Physiol Heart Circ Physiol 291:H846$\mathrm{H} 853$

28. Verma NK, Dey CS (2006) Anti-leishmanial drug miltefosine causes insulin resistance in skeletal muscle cells in vitro. Diabetologia 49:1656-1660

29. Schaller MD (2001) Biochemical signals and biological responses elicited by the focal adhesion kinase. Biochim Biophys Acta 1540:1-21

30. Ilic D, Kovacic B, Johkura K et al (2004) FAK promotes organization of fibronectin matrix and fibrillar adhesions. J Cell Sci 117:177-187

31. Annabi SE, Gautier N, Baron V (2001) Focal adhesion kinase and Src mediate integrin regulation of insulin receptor phosphorylation. FEBS Lett 507:247-252

32. Lebrun P, Baron V, Hauck CR, Schlaepfer DD, Obberghen EV (2000) Cell adhesion and focal adhesion kinase regulates insulin receptor substrate-1 expression. J Biol Chem 275:38371-38377

33. Lebrun P, Mothe-Satney I, Delahaye L, Obberghen EV, Baron V (1998) Insulin receptor substrate-1 as a signaling molecule for focal adhesion kinase pp125FAK and pp60src. J Biol Chem 273:32244-32253

34. Farese VR (2002) Function and dysfunction of aPKC isoforms for glucose transport in insulin-sensitive and insulin-resistant states. Am J Physiol Endocrinol Metab 283:E1-E11

35. Hirai T, Chida K (2003) Protein kinase C: activation mechanisms and cellular functions. J Biochem 133:1-7
36. Webb BLJ, Hirst SJ, Giembycz MA (2000) Protein kinase C isoenzymes: a review of their structure, regulation and role in regulating airways smooth muscle tone and mitogenesis. $\mathrm{Br} \mathrm{J}$ Pharmacol 130:1433-1452

37. Muller G, Wied S, Frick W (2000) Cross talk of pp125FAK and pp59Lyn nonreceptor tyrosine kinase to insulin-mimetic signaling in adipocytes. Mol Cell Biol 20:4708-4723

38. Lin YS, Itani SI, Kurowski TG et al (2001) Inhibition of insulin signaling and glycogen synthesis by phorbol dibutyrate in rat skeletal muscle. Am J Physiol Endocrinol Metab 281: E8-E15

39. Sajan MP, Rivas J, Li P, Standaert ML, Farese RV (2006) Repletion of atypical protein kinase $\mathrm{C}$ following RNAi-mediated depletion restores insulin-stimulated glucose transport. J Biol Chem 281:17466-17473

40. Tremblay F, Lavigne C, Jacques H, Marette A (2001) Defective insulin-induced GLUT4 translocation in skeletal muscle of high fat-fed rats is associated with alterations in both Akt/protein kinase $\mathrm{B}$ and atypical protein kinase $\mathrm{C}(\zeta / \lambda)$ activities. Diabetes 50:1901-1910

41. Kotliar N, Pilch PF (1992) Expression of the glucose transporter isoform GLUT4 is insufficient to confer insulin regulatable hexose uptake to cultured muscle cells. Mol Endocrinol 6:337-345

42. Olson AL, Trumbly AR, Gibson GV (2001) Insulin-mediated GLUT4 translocation is dependent on the microtubule network. J Biol Chem 276:10706-10714

43. Liu LB, Omata W, Kojima I, Shibata H (2003) Insulin recruits GLUT4 from distinct compartments via distinct traffic pathways with differential microtubules dependence in rat adipocytes. J Biol Chem 278:30157-30169

44. Fletcher LM, Welsh GI, Oatey PB, Tavare JM (2000) Role for the microtubule cytoskeleton in GLUT4 vesicle trafficking and in the regulation of insulin- stimulated glucose uptake. Biochem $\mathrm{J}$ 352:267-276

45. Olson AL, Eyster CA, Duggins QS, Knight JB (2003) Insulin promotes formation of polymerised microtubules by a phosphatidylinositol 3-kinase-independent, actin-dependent pathway in 3T3-L1 adipocytes. Endocrinology 144:5030-5039

46. Patel N, Rudich A, Khayat ZA, Garg R, Klip A (2003) Intracellular segregation of phosphatidylinositol-3,4,5-trisphosphate by insulin-dependent actin remodeling in L6 skeletal muscle cells. Mol Cell Biol 23:4611-4626

47. Palazzo AF, Eng CH, Schlaepfer DD, Maracantonio EE, Gundersen GG (2004) Localized stabilization of microtubules by integrin- and FAK-Facilitated Rho signaling. Science 303: 836-839 